months. The radiological examination was performed in the following ratio: X-rays - 91 (100.0\%), CT - 79 (86.8\%), MRI - 66 (72.5), including MRI "whole body" with 15 pts, bone scintigraphy - 54 (59.3\%). Monofocal form was registered in 1/3 cases. 2/3 cases was presented as a typical multifocal process with predominant involvement femur - $37(40.7 \%)$, bone of foot - $36(39.6 \%)$, tibia - $33(36.3 \%)$, spine $-29(31.9 \%)$. The number of foci is $3.0(1.0 ; 6.0)$. We did not revealed any significant differences in quantity of WBC, platelets, hemoglobin level, ESR, CRP). Evidence confirming NBO was a negative bone biopsy in $100.0 \%$ cases. However, morphological data were as non-specific, as granulomatous inflammation.

Conclusions: NBO is determined as a primarily chronic multifocal process without specific clinical and laboratory peculiarities, associated with immune-mediated diseases. Diagnose must be established on morphological and bacteriological data bone biopsy.

Disclosure of Interest: None declared

DOI: 10.1136/annrheumdis-2017-eular.1749

\section{AB0963 LIPID ABNORMALITIES IN CHILDREN AND ADOLESCENTS WITH SYSTEMIC LUPUS ERYTHEMATOSUS}

L.F. Bogmat, N.S. Shevchenko, I.N. Bessonova, V.V. Nikonova. Department of Cardiorheumatology, Institute of Children and Adolescents Health Care, Kharkiv, Ukraine

Background: Systemic lupus erythematosus is an autoimmune disease that leads to the progressive destruction of the vital organs and systems, promotes early disability, premature mortality. The main reasons for the latest adult population of patients have complications of atherosclerotic vascular lesions stuch as the myocardial infarction and the stroke. The greatest effectiveness of preventive measures of the progression of atherosclerotic process and its associated cardiovascular complications determine the maximum early to start immediately after diagnosis in childhood and adolescence.

Objectives: To evaluate the lipid spectrum of the blood of children and adolescent patients with SLE.

Methods: It was been examined 26 persons $7-18$ years with systemic lupus erythematosus, mostly female ( $88.46 \%)$, which were determined by the concentration of total cholesterol (total cholesterol), HDL cholesterol (HDL cholesterol), low density lipoprotein cholesterol (LDL), triglycerides (TG), calculated coefficient of the atherogenicity ( $\mathrm{CA}=$ (total cholesterol $-\mathrm{HDL}$ cholesterol)/HDL cholesterol). Distribution groups conducted depending on the duration of the disease: the first consisted of 10 patients $(38.46 \%)$ with a term of $1-3$ years of the disease, the second - 16 people $(61,54 \%)$ with duration of more than 3 years. The control group consisted of 10 healthy peers.

Results: Average lipid spectrum of the blood of patients did not exceed the reference values and had no statistical differences in the patients allocated to groups. However, in comparison with the control group the children with SLE had significant differences that reflect the peculiarities of formation of their metabolic disorders. Thus, total cholesterol and TG levels in both the first and the second groups were significantly higher than the control value and accounted for $(5,02 \pm 0,26) \mathrm{mmol} / \mathrm{L}(5,24 \pm 0,26) \mathrm{mmol} / \mathrm{L}$ vs $(3,39 \pm 0,20) \mathrm{mmol} / \mathrm{L}(\mathrm{p}<0,05)$ and $(1,64 \pm 0,54) \mathrm{mmol} / \mathrm{L}(1,45 \pm 0,19) \mathrm{mmol} / \mathrm{L}$ vs $(0,72 \pm 0,08) \mathrm{mg} / \mathrm{L}(\mathrm{p}<0.05)$, respectively. Similar changes had occurred with parameters of LDL cholesterol, which significantly increased among patients with disease duration of 1-3 years $((3,08 \pm 0,26) \mathrm{mmol} / \mathrm{L}$ vs $(1,73 \pm 0,03) \mathrm{mg} / \mathrm{dL}$ in the control group; $\mathrm{p}<0.05)$ and reached biggest values in patients with SLE over the course of 3 years $((3,57 \pm 0,82)$ $\mathrm{mmol} / \mathrm{l}, \mathrm{p}<0.05)$. In parallel, the concentration of $\mathrm{HDL}$ cholesterol patients of the second group decreased $((1,38 \pm 0,06) \mathrm{mmol} / \mathrm{L}$ vs $(1,51 \pm 0,08) \mathrm{mg} / \mathrm{dL}$ healthy subjects, $p<0.1)$, the consequence was significant increase in their spacecraft $((2,79 \pm 0,69)$ conv. units. against $(1,24 \pm 0,17)$ conv. units. in comparison group, $\mathrm{p}<0.05)$.

In addition, patients with SLE found a direct correlation of total cholesterol blood of disease activity, confirmed a direct correlation $(r=0,632 ; p<0.05)$.

Conclusions: Thus, changes of blood lipid profile in the SLE patients occur in the early stages of the disease in childhood and adolescence, have the atherogenic focus, which compounded with increasing the duration and disease activity.

Disclosure of Interest: None declared

DOI: 10.1136/annrheumdis-2017-eular.6569

\section{AB0964 SOME PECULARITIES OF THE COURSE OF JUVENILE IDIOPATHIC ARTHRITIS IN PATIENTS TREATED WITH TOCILIZUMAB}

O.A. Oshlyanska, A.G. Artsymovych. Connective Tissue Disorders in Children, State Institute of Pediatrics, Obstetrics and Gynecology, Academy of Medical Sciences of Ukraine, Kyiv, Ukraine

Background: The introduction of biological therapy drugs contributes to changing the natural course of the disease in cases of severe JIA.

Objectives: To clarify impact of tocilizumab on the course of JIA.

Methods: Of 117 children with JIA being under observation for the last five years $35 \%$ receive biologic therapy ( 3 etanercept, 21 adalimumab, 11 tocilizumab) during 1-5 years. Retrospective analysis of the data from clinical, laboratory and instrumental studies in the dynamics of the TCZ treatment of patients with JIA was made.
Results: Among children treated with TCZ 63,6\% were sJIA cases, $63,6 \%$ were female. Age of onset $6,1 \pm 4,7 y(6 \mathrm{~m}-10,5 \mathrm{y})$, all had acute onset, hyperthermia, severe pain syndrome, exudative arthritis in all pJIA cases and half of SJIA cases. ESR $39,7 \pm 11,2 \mathrm{~mm} / \mathrm{h}$, CRP $53,8 \pm 16,1 \mathrm{mg} / \mathrm{L}$, all patients had anemia, leukocytosis and were seronegative for RF and anti-CCP, 3 of pJIA patients revealed ANA (1:1200-2400), IL-6 19,78 $\pm 6,7 \mathrm{pg} / \mathrm{ml}$. Before biological therapy has begun, SJIA courses were continuously relapsing in all cases with $4,7 \pm 2,1$ exacerbations per $y$; during the 1 st y of illness 8 cases run with coxitis, 7-cervical spine involvement, 9-wrists damage. All patients received CS therapy before initiating TCZ, 45,4\% of them with pulse therapy, all marked by the inability to minimize the CS dose, all received 2-4 DMARDs in high doses. 2 patients received adalimumab before TCZ treatment. Elapsed time from the onset to biological agent prescription was $5,37 \pm 5,1$ years. At the start of biological therapy JADAS was $19,6 \pm 5,7$, stunted growth $-1,88 \pm 0,3 \sigma$, according to densitometry, osteoporosis took place in every case $(Z=-2,7 \pm 1,1)$. After 6 month JADAS was $1,8 \pm 1,1$, ESR and CRP normalized, IL-6 rate remained high in $36 \%$ cases. After 1 year the severity of osteoporosis decreased $(Z=-1,17 \pm 0,8)$, bone deficiency depended on duration of TCZ exposure $(r=-0,72)$ and on the elapsed time from onset of JIA before the start of biological therapy $(r=-0,84)$. The mean increase in height was 7.73 $\mathrm{cm} /$ patient-year $(+1 \pm 0,8 \sigma)$. Stunted growth depended on the duration of the TCZ course $(r=-0,81)$ and the elapsed time from the onset of the disease to the start of biological therapy $(\mathrm{r}=-0,72)$. After 1 y of TCZ all children had normal weight and BMI for age $(19,89 \pm 1,9)$. After $1-5$ ys of treatment JADI was evaluated $2,1 \pm 2,9(0-7)$, the degree of joint damage didn't depend on the duration of the biological therapy $(r=0,24)$ and correlated with the time elapsed from the onset of the disease before treatment $(r=0,59)$. During the treatment, exacerbations were marked only in 1 case, adverse events in 3 cases (skin infections, leukopenia). TCZ therapy allowed to completely discontinue CS in $63,6 \%$ cases, minimize them to $4 \mathrm{mg} / \mathrm{day}$ in others, DMARDs are discontinued in $9 \%$ cases.

Conclusions: Administration of TCZ is rather effective towards the drug induced remission even in long-time JIA process, but the least joint damage, osteoporosis and stunted growth can be obtained with earlier tocilizumab prescription. Reclassification of patients according to specific clinical and immunological features leads to optimization of the selection of targeted therapy.

\section{References:}

[1] While identifying in onset of JIA polyarticular destruction and systemic features (hyperthermia, anemia, leukocytosis, high laboratory activity and severity of osteoporosis) one should consider the feasibility of early administration of tocilizumab.

Disclosure of Interest: None declared

DOI: 10.1136/annrheumdis-2017-eular.2715

\section{AB0965 EVALUATION OF BONE MINERAL DENSITY IN CHILDREN WITH CHRONIC RECURRENT MULTIFOCAL OSTEOMYELITIS AT DIAGNOSIS}

Ö. Sert ${ }^{1}$, E. Çomak ${ }^{2}$, G. Kaya Aksoy ${ }^{2}$, A. Gemici ${ }^{2}$, M. Koyun ${ }^{2}$, S. Akman ${ }^{2}$. ${ }^{1}$ Pediatrics; ${ }^{2}$ Department of Pediatric Nephrology and Rheumatology, Akdeniz University School of Medicine, Antalya, Turkey

Background: Chronic recurrent multifocal osteomyelitis (CRMO) is a rare autoinflammatory disorder that has sterile bone inflammation as a main phenotypic feature. Diagnosis of CRMO is based on typical clinical and radiologic findings and presence of some inflammatory markers. Plain radiographs, technetium bone scan and MRI may be used for diagnosis of children with suspected CRMO. Despite data for other imaging methods in chidren with CRMO, little information is available regarding the bone mineral density.

Objectives: The aim of the study was to evaluate bone mineral density (BMD) findings in children with CRMO at time of diagnosis.

Methods: The medical records of children with CRMO were reviewed retrospectively. Children who met Bristol diagnostic criteria were included in the study. Clinical and laboratory findings, bone scan and MRI features were analyzed. Bone mineral density was measured by DEXA technique at femoral neck and lumbar spine regions; a Z-score $<-2$ was considered as osteoporosis.

Results: A total of 6 patients, one girl and 5 boys, with a median age of 10 years (4 - 14 years) and a median follow-up period of 38.5 months ( $3-72$ months) were included in the study. MRI and whole body technetium bone scan were performed at 6 and 4 children, respectively and detected at least two lesions $\mathrm{MRI}$ or bone scans. Osteoporosis was detected in 5 patients at diagnosis. Bone mineral density Z-scores were median $-2.9[-4.9 \pm(-2,4)]$ and $-2.9[-4,1-(-1,8)]$ at femoral neck and lumbar spine, respectively.

Conclusions: Osteoporosis is common in children with CRMO, it may be related with disease spectrum. Evaluation of bone mineral density abnormalities at time of diagnosis and during therapy may be a part of primary care in children with CRMO.

Disclosure of Interest: None declared

DOI: 10.1136/annrheumdis-2017-eular.4452 